SSN-94-17

\title{
INFCIRC/153 AS THE BASIS FOR VERIFICATION OF A SPECIAL NUCLEAR MATERIALS PRODUCTION CUTOFF CONVENTION
}

\author{
RAYMOND PARSICK \\ JONATHAN SANBORN
}

BROOKHAVEN NATIONAL LABORATORY

AUGUST, 1994 


\section{DISCLAIMER}

This report was prepared as an account of work sponsored by an agency of the United States Government. Neither the United States Government nor any agency thereof, or any of their employees, makes any warranty, express or implied, or assumes any legal liability or responsibility for the accuracy, completeness, or usefulness of any information, apparatus, product, or process disclosed, or represents that its use would not infringe privately owned rights. Reference herein to any specific commercial product, process, or service by trade name, trademark, manufacturer, or otherwise, does not necessarily constitute or imply its enforcement, recommendation, or favoring by the United States Government or any agency thereof. The views and opinions of authors expressed herein do not necessarily state or reflect those of the United States Government or any agency thereof. 


\section{DISCLAIMER}

Portions of this document may be illegible in electronic image products. Images are produced from the best available original document. 
SSN-94-17

\title{
INFCIRC/153 as the Basis for Verification of a Special Nuclear Materials Production Cutoff Convention
}

\author{
Raymond Parsick \\ Jonathan Sanborn \\ Brookhaven National Laboratory
}

\begin{abstract}
Although safeguards practice under the Nuclear Non-Proliferation Treaty (NPT) has evolved considerably over the lifetime of the agreement, INFCIRC/153 remains the defining document of NPT verification. It is the only available document that might be adopted as an element of a special nuclear materials production cutoff convention to define an "NPT-like" verification regime. The clearly stated objective of INFCIRC/153 safeguards is the ability to "detect diversion," which is achieved by verifying the state's nuclear material accounting system. Although the way in which the verification objectives of a cutoff convention will be formulated is not yet known, it is clear that there will not be an exact fit between the two. The mismatch becomes greater to the extent that material in declared facilities is "grandfathered" under cutoff. It also increases as a cutoff regime focuses verification on the physical process of production (in operating facilities) or on facility operational status or capability (at non-operating facilities) rather than on the nuclear material itself.
\end{abstract}

\section{Introduction}

It is expected that the International Atomic Energy Agency (IAEA), which provides the verification function for the NPT, will assume a similar role under the proposed cutoff convention. NPT safeguards play a central role in non-proliferation policy, and provide a well-defined technical standard for the verification of nuclear facilities. It is often assumed that NPT-like safeguards will form the verification regime of the cutoff convention.

The NPT itself does not have an annex on verification; this role is assumed by a document separate from the treaty itself, the IAEA document INFCIRC/153 (Corrected) ${ }^{1}$, which was the product of very extensive discussions ${ }^{2}$ after the NPT came into force. The IAEA's Board of Governors directed the Director General to use this document as a basis for negotiating the safeguards agreements between the IAEA and each non-nuclear weapons state party to the NPT; it is these state agreements which are the legal basis for inspection activities in the state.

This paper compares the technical objectives which may be assigned to the IAEA under a cutoff convention with those described in INFCIRC/153. It also deals with means and limitations of verification activities which are closely linked to these objectives. The broader political and legal objectives associated with the convention are not considered. 
2. Technical Objectives of IAEA Verification under NPT Safeguards and INFCIRC/153

INFCIRC/153 defines the scope, objectives, and methods of verification under the NPT. It is sometimes called the "model" NPT agreement; each state-IAEA agreement follows INFCIRC/153 closely. The state and the IAEA Director General may propose variations in the content of the state agreement, but each agreement must be approved by the IAEA Board and then circulated as an IAEA INFCIRC document. Thus, each change is open to scrutiny. ${ }^{3}$ However, there are more detailed arrangements ("Subsidiary Arrangements") that do not require the approval of the Board which are treated as "safeguards confidential." These Subsidiary Arrangements, including what are called "Facility Attachments" describe safeguards activities at a more detailed level and, thus, affect their implementation.

To date, all approved NPT agreements contain the following language:

"The objective of safeguards is the timely detection of diversion of nuclear material from peaceful nuclear activities to the manufacture of nuclear weapons or of other nuclear explosive devices or for purposes unknown, and deterrence of such diversion by the risk of early detection."

This concept is reinforced by the following phrase in Articles 1 and 2 of each approved safeguards agreement:

" . . f for the exclusive purpose of verifying that such material is not diverted to nuclear weapons or other nuclear explosive devices."

Consequently, the IAEA's rights of inspection under an NPT safeguards agreement apply almost exclusively to nuclear material at "strategic points."4 (Other rights, having to do with verification of facility design features, and performing special inspections, are considered below).

The central concept of "detection of diversion" takes on a very specific meaning in the context of the verification methods described in INFCIRC/153. A non-nuclear weapons state signatory to the NPT must periodically report of all transfers and inventories of nuclear material to the IAEA; in turn, the LAEA verifies these reports by auditing records and by independent observations, including measurements of the material presented to inspectors. A "diversion" is indicated as an apparent shortage of material in this accounting scheme; it is also detected if reports are inconsistent, or if an amount of nuclear material observed or measured does not correspond to the reports. This verification method is referred to below as "full material balance verification."5

There are legal, financial, and technical limitations to the scope of IAEA verification activities undertaken pursuant to these technical objectives. For example, the IAEA cannot inspect "source material,"6 material that a state has declared it is using in nonnuclear activities, ${ }^{7}$ or material for which the IAEA previously agreed that safeguards could be terminated. 8

Events in Iraq caused the IAEA Board of Governors to consider measures to strengthen IAEA safeguards under "comprehensive safeguards agreements," in particular, those based on INFCIRC/153. This included two measures which can be expected to improve safeguards in a way that will be useful for a cutoff convention. First, the Board 
reconfirmed the right of the IAEA to conduct "special inspections," which may afford inspectors access to "additional locations" (e.g., locations outside of declared facilities), according to the terms of the state agreement. This reconfirmation does not reduce the right of the state to be consulted, as is required by such agreements.

Second, the Board interpreted the requirement in such state agreements "that [design information] in respect of new facilities shall be provided as early as possible before nuclear material is introduced into a new facility" to mean that the information should be provided in an iterative manner starting before construction, and continuing until the facility is dismantled, even if it is declared to be permanently shut down before dismantlement is completed. The IAEA has a right under INFCIRC/153 to verify design information during visits to facilities. It is not yet clear how often the IAEA inspectors will be able to re-verify the design information, especially for facilities without nuclear material.

Other developments affect the implementation of NPT safeguards. A good example is the "Limited Frequency Unannounced Access" (LFUA) inspection strategy developed by the "Hexapartite Safeguards Project" (HSP). 9 The LFUA strategy is designed to detect the production of highly enriched uranium in gas centrifuge enrichment plants declared for production of low-enriched uranium. In the HSP negotiations the United States argued that such a capability was necessary, while the Japanese and Europeans took the position that it was not required by INFCIRC/153. The final HSP report endorsed LFUA, and this approach was included in the relevant facility attachments.

The current practice of "NPT safeguards" is the result, then, not only of the content of INFCIRC/153, but of the negotiations of state agreements and subsidiary arrangements, of other agreements, of statements of policy by the IAEA Board, and of the adoption of internal IAEA Secretariat guidelines. ${ }^{10}$ However, because there is no formal, accepted document which encompasses all of this material, INFCIRC/153 remains the only available document that might be incorporated into a cutoff convention designed to follow "NPT safeguards".

\section{Likely Technical Objectives of IAEA Verifications under a Cutoff Convention}

Although the technical objectives of a cutoff convention have not yet been defined, and will probably be the subject of debate in the Conference on Disarmament, they are likely to be constrained by the following conditions:

- The basic undertaking of the convention probably will follow fairly closely the Clinton formulation which would prohibit the ". . production of highly enriched uranium (HEU) or plutonium for nuclear explosive purposes or outside of safeguards."

and,

- The weapons states will not place nuclear weapons or weapons stockpile material under a verification regime; in other words, at least some material will be "grandfathered." The precise extent of this grandfathering is unclear.

We can draw the following conclusions: 
- The technical objectives will have to include a capability to verify: (1) that the declared amounts of material produced correspond to the material presented for verification; (2) that more than the declared quantities have not been produced at facilities where production is declared; and (3) that no production is occurring at other locations.

- The verification objectives will include the safeguarding of any HEU and plutonium "produced" after entry-into-force (EIF), to assure that this material is not being used for weapons.

- Not all material in a state will be verified or inspected in a cutoff convention verification regime.

We note that "production" of plutonium generally is taken to mean separation in a reprocessing plant, rather than transmutation in a reactor. Thus in the narrowest interpretation of the objectives of the convention, the only material subject to verification would be that described by the second bullet, above. This interpretation would exclude all plutonium in separated form at EIF.

\section{Comparison of Technical Objectives}

The technical objectives of the cutoff convention verification overlap with, but are not identical to, the concept of "detection of diversion" in INFCIRC/153. Areas of discrepancy can be described as follows.

\section{Detection of Production in Excess of Declared Amounts}

The ability to verify that no excess material beyond declared amounts has undergone chemical separation (for plutonium), or isotopic enrichment to HEU (for uranium) does not automatically follow from the INFCIRC/153 material-accounting verification scheme. For example, under current NPT safeguards the IAEA has a very limited ability to detect overproduction of LEU (production of greater than declared amounts) using undeclared feed, at a centrifuge-enrichment facility. This is because such overproduction does not involve a detectable "diversion" from the declared material balance. ${ }^{11}$ This situation is deemed acceptable for enrichment facilities currently inspected under the NPT, where there should not be any source of unsafeguarded feed. However, such a limited verification scheme would be unacceptable under a cutoff convention in a plant declared for HEU production, where the existence of unsafeguarded material is assumed. Achieving the verification objectives of the cutoff convention will require monitoring the physical production processes at facilities capable of such processes. ${ }^{12}$ We note that in some situations, such as at reprocessing plants, a form of such monitoring is done by the IAEA. ${ }^{13}$

As noted above, the IAEA has the ability to verify "design information." Such visits can help to assess the maximum amount of nuclear material that could be produced in a facility but would not detect extra, unreported production of HEU or plutonium within the estimated maximum.

\section{"Grandfathering" and Scope}

Whether full material balance verification is useful to fulfill the objectives of a cutoff convention depends on what material is considered to be "grandfathered". If the inventory 
of a reprocessing plant at EIF is deemed to be subject to the conditions of the treaty, then that inventory would have to be declared and verified, along with any plutonium separated after EIF; in effect this would be full material accountancy verification, and would be quite consistent with verification under INFCIRC/153.

However, if some of the inventory in the facility ${ }^{14}$ is "grandfathered," applying full material accountancy verification encounters the problem that the inspectorate may not know whether a nuclear material shortage was one of material subject to the treaty, or whether it was of grandfathered material. If the state does not declare the inventory of grandfathered material (which, after all, is not subject to the treaty), full material balance verification is not possible. This situation lends itself to a different type of accounting verification, ${ }^{15}$ which simply compares the amount of material separated ("produced") to the amount of material placed under safeguards, ignoring the inventory of grandfathered material.

INFCIRC/153 states that safeguards are to be applied to ". . . all peaceful nuclear activities within the territory of the state." Certainly, fresh LEU fuel in commercial reactors and fabrication facilities are covered by this phrase. Yet this material is only indirectly relevant to the basic undertaking of a cutoff convention, and the convention may not require inspection of this and similar materials.

\section{Status of Non-Producing Facilities}

The objective of detecting the diversion of nuclear material when there is no material to divert makes no sense; hence, INFIRC/153 safeguards do not apply to facilities with no declared nuclear material inventory. Yet under a cutoff, it might be decided that it is necessary to verify that a facility that has the capability to "produce" plutonium or HEU should be monitored to verify that it is not being operated in this way. Such monitoring may be an important part of the cutoff convention. ${ }^{16}$

Finally, consider the application of INFCIRC/153 safeguards to a shut-down, inoperable, gaseous diffusion plant or reprocessing plant, which is being decontaminated. INFCIRC/153 safeguards would focus on the nuclear material inventory of the facility, and on the material that was being removed from it. If this material was "grandfathered," this activity and effort would be irrelevant to the purposes of a cutoff convention.

\section{Conclusion}

If INFCIRC/153 was used to define the verification regime of a Cutoff convention, INFCIRC/153 language would have to stand on its own; 17 it is therefore appropriate in this context to consider this language without reference to subsequent agreements and technical evolution. Two major areas of discrepancy are apparent between the requirements for verifying a cutoff convention and the system of objectives and methods described in INFCIRC/153 .

The first discrepancy is that INFCIRC/153 does not have a verification requirement for monitoring the physical process of "producing" plutonium or HEU. The ability to verify that overproduction is not occurring in a chemical or isotopic separation process does not result from the capability to "detect diversion" through material balance accounting. Rather, this can be accomplished by monitoring the actual production process. Such a capability would appear to be a fundamental requirement of verification under the cutoff 
convention. This is not to say that such verification could not take place under INFCIRC/153; in fact, it does in certain cases.

The second problem is that the existence of both grandfathered material and material subject to the convention within the same facility renders fundamental mechanisms of verification in INFCIRC/153 inappropriate. The importance of this problem will depend on the way in which grandfathering is defined in the cutoff convention.

\section{Acknowledgment}

The authors are grateful for the helpful comments of C. Ruth Kempf, Alan Labowitz, Ming-Shih Lu and William Stanbro.

\section{Footnotes}

1 This document has the title "The Structure and Content of Agreements between the Agency and States Required in Connection with the Threat on the Non-Proliferation of Nuclear Weapons"; it. is often referred to as a model NPT agreement.

2 INFCIRC/153 was generated by the Safeguards Committee of the Board of Governors, which was open to all members of the IAEA.

3 For example, the Board has approved protocols to some NPT safeguards agreements that emphasize the need for the IAEA to cooperate with the State's or region's system of accounting and control of nuclear material and to avoid duplication of such activities.

4 "Strategic points" are locations in the facility to which inspectors are given access for purposes of verification.

5 "Full material balance accounting" includes verification of facility inventories, inputs, and outputs; thus full material balance accounting implies verification of the equation:

\section{Beginning Inventory + Inputs - Ending Inventory - Outputs = Material Unaccounted For (MUF)}

A positive value of "MUF" indicates an apparent shortage of material.

6 Uranium in mining or ore processing activities

7 In addition, material can be withdrawn after safeguards have been applied, through the provisions of Article 14 of the state agreement which provides for withdrawal for military but nonexplosive uses. Questions can be raised about the need to declare material already in such uses at the time the state ratifies its agreement with the IAEA.

8 This material may be waste in a form not economically suitable for recovery.

9 The Hexapartite Safeguards Project was a negotiation undertaken in the mid-1980s to establish the safeguards approach for centrifuge enrichment plants. The participants were the U.S., Japan, URENCO, Australia, the IAEA, and EURATOM. The LFUA strategy allows short-notice access to the gas centrifuge cascade to detect HEU.

10 An example would be, the "91 - 95 Criteria" which describe in detail how safeguards technical objectives should be fulfilled at specific types of facilities.

11 There will be no detection of diversion because the reports to the IAEA will be self-consistent (although they will not reflect the total throughput of the facility), and because all the material presented to the IAEA for verification will be consistent with declarations. This can occur because the undeclared feed material is available to "make the books balance," to that no material appears to be missing. One's checking account will still balance if extra deposits and withdrawals are made, provided they sum to zero. 
12 Another situation in which material accountancy verification alone must be viewed as inadequate would be a blending operation of the type involved in the Russian HEU purchase. Material balance verification activities by themselves will not detect the substitution of low-enriched uranium for HEU unless the blending operation itself is monitored.

13 Because the first point where an accurate value can be assigned to the plutonium content in spent fuel is at the accountability tank in a reprocessing plant, the IAEA continuously monitors the passageway taken by spent fuel into the reprocessing area. This would allow the IAEA to detect production over declared amounts.

14 This material should be thought of as in-process material that may be mixed with material subject to the treaty, either physically or in the accounting structure. Clearly, "grandfathered" material that is entirely separate, such as product material in a separate vault, can be ignored.

15 This type of verification would only seek to verify the equation:

Inputs (material separated) - Outputs (product material placed under safeguards) $=$ MUF.

${ }^{16}$ Such facilities will exist under the scope of the convention. In the U.S., consider the Centrifuge Plant Demonstration Facility in Oak Ridge (operable, but with no inventory), the calutron facility at Y-12 (which separates non-uranium isotopes), and, of course, the large number of hot cells.

17 For example, would Pakistan feel bound by the results of the HSP (in which it did not participate) or take the position (which was that of the Japanese at one time) that inspection to detect HEU production (at a plant declared to be producing LEU) was not justified under INFCIRC/153? 